\title{
Matrix metalloproteinase expression in high grade soft tissue sarcomas
}

\author{
STEPHANIE H. ALFORD ${ }^{1}$, MICHAEL S. VRANA ${ }^{1}$, LINDSAY WAITE ${ }^{3}$, \\ JOSEFINE HEIM-HALL ${ }^{2}$, VICTOR L. SYLVIA ${ }^{1}$ and RONALD P. WILLIAMS ${ }^{1}$
}

Departments of ${ }^{1}$ Orthopaedics, ${ }^{2}$ Pathology, and ${ }^{3}$ Epidemiology and Biostatistics, The University of Texas

Health Science Center at San Antonio, San Antonio, TX 78229-3901, USA

Received May 2, 2007; Accepted June 28, 2007

\begin{abstract}
Soft tissue sarcomas comprise a heterogeneous group of mesenchymal tumors with varying biological behavior ranging from indolent tumors with no or minimal metastatic risk to aggressive and frequently metastasizing tumors. Among the more common aggressive adult soft tissue sarcomas are malignant fibrous histiocytoma, synovial sarcoma and liposarcoma. Matrix metalloproteinases are enzymes which perform a homeostatic role in mesenchymal tissue and function in both tumorigenesis and metastasis. The objectives of this study are to determine the presence and relative quantity of matrix metalloproteinases (MMPs) -1, -2, -8, -9, and -13; extracellular matrix metalloproteinase inducer (EMMPRIN); and tissue inhibitors of matrix metalloproteinases (TIMP)-1 and -2 in high grade soft tissue sarcoma tumor specimens using real-time PCR. The second objective is to determine if a relationship exists between quantity of EMMPRIN, MMPs, and TIMPs expressed in tumor tissue and disease-free survival. One hundred and forty patients diagnosed with high grade soft tissue sarcomas between 1995-2003 were identified. Tissue blocks and histologic slides were acquired for 41 specimens. Tumor specimens included 29 malignant fibrous histiocytomas, 3 liposarcomas and 11 synovial sarcomas. RNA was extracted and RT-PCR was performed in triplicate. No significant differences were found between the three types of high grade soft tissue sarcomas studied and the expression of MMPs. Interestingly, no relationship was found between high or low levels of MMPs when compared with disease-free survival. Our data support other research which finds variable correlation between MMP expression in soft tissue sarcomas and disease-free survival. We assert that the difference in
\end{abstract}

Correspondence to: Dr Stephanie Alford, Department of Orthopaedics, University of Texas Health Science Center at San Antonio, 7703 Floyd Curl Drive, MC 7774, San Antonio, TX 78229-3901, USA

E-mail: alfords@uthscsa.edu

Key words: matrix metalloproteinases, MMPs, high grade soft tissue sarcomas, MFH, liposarcoma, synovial sarcoma correlation between MMP expression in carcinomas and sarcomas and disease-free survival is based on the vast phenotypic and genotypic difference between the cells of origin.

\section{Introduction}

Soft tissue sarcomas (STS) are a broad category of uncommon tumors which arise from pluripotent mesenchymal stem cells including fibroblasts, myocytes, adipocytes, osteocytes and chondrocytes $(1,2)$. The worldwide incidence of STS is estimated at 20 cases per one million people per year (3). According to the American Cancer Society, in 2006, 9,530 people will be diagnosed with STS, and 3500 people will die of the disease. The overall 5-year relative survival rate for soft tissue sarcomas is $70 \%$ (4).

The most important prognostic factor for soft tissue sarcomas is histologic grade. Several grading systems exist, but none is entirely predictive in all cases. Histological subtype alone may define tumor grade in a group of these tumors, while for some STS subtypes, grading criteria are not applicable, either because they have not been sufficiently established or because they do not sufficiently correlate with prognosis. Nonetheless, staging systems in the United States require a tumor grade, and treatment decisions are often made based on whether a tumor is considered low or high grade. Therefore, grading of STS should be attempted whenever possible. Among the most widely used grading systems are the FNCLCC (French Federation Nationale des Centres de Lutte Contre le Cancer) and the NCI (United States National Cancer Institute) grading system. Both of these are three-tiered systems which use a combination of histological type, cellularity, pleomorphism and mitotic rate as well as percent necrosis to determine grade. When applying these criteria, the sarcomas included in this study are classified as grade $2 / 3$ or $3 / 3$, with the latter being the most common grade. Since grade 2 tumors are mostly treated clinically in a fashion similar to grade 3 tumors, they will be referred to as 'high grade soft tissue sarcomas' (HGSTS) for the purpose of this study (5).

Other prognostic factors that are included in the American Joint Committee on Cancer (AJCC) staging criteria include: size, depth, and distant spread (6). In general, well differentiated (low grade), superficial tumors $<5 \mathrm{~cm}$ in size and without distant spread have a $90 \%$ survival rate. Poorly differentiated or dedifferentiated (high grade) tumors that are 
deep to the fascia and $>5 \mathrm{~cm}$ without distant spread have a survival rate of $56 \%$ (6).

Malignant fibrous histiocytoma (MFH), pleomorphic liposarcoma and synovial sarcoma are examples of high grade soft tissue sarcomas (HGSTS) and are among the most common soft tissue sarcomas of the extremities $(1,2,3,7,8)$. $\mathrm{MFH}$ accounts for $28 \%$ of soft tissue sarcomas and liposarcoma accounts for approximately $15 \%$, although the number of high grade forms of liposarcoma (dedifferentiated or pleomorphic) is substantially less $(1,6)$. Synovial sarcoma represents approximately $10 \%$ of all STS $(6,9)$.

Treatment of HGSTS consists of radiation followed by wide surgical resection versus wide resection followed by adjuvant chemotherapy and/or radiation. Despite treatment, the overall 5-year survival rate in patients with soft tissue sarcomas of all stages remains only 50-60\% with death usually due to lung metastasis (10). A population based Swedish study of all soft tissue sarcomas diagnosed between 1964 and 1989 showed the 5-year metastasis-free survival rate to be 58, 37 and $33 \%$ respectively for MFH, high grade liposarcoma and synovial sarcoma (2). The above data confirm that high grade soft tissue sarcomas (HGSTS) are aggressive tumors and current therapies are inadequate. Without a better understanding of the biochemical environment in which high grade soft tissue sarcomas grow and metastasize, novel treatment and improved survival is not likely.

One area of study that has the potential for impacting both cancer diagnosis and treatment is the study of matrix metalloproteinases (MMPs). MMPs are a family of over 20 structurally related proteolytic enzymes involved in cleavage of various components of the extracellular matrix (ECM). These enzymes function to maintain homeostasis of the ECM during normal cellular processes such as, bone remodeling, connective tissue development, embryo implantation, embryogenesis, fibrinolysis, and wound healing (11-14). In bone tissue, they are responsible for the initiation of normal bone resorption as well as linking resorption to bone formation (12). While essential to the normal physiologic function of the extracellular matrix, matrix metalloproteinases have been linked to numerous pathologic processes including, tumor angiogenesis, chronic ulcers, liver fibrosis, asthma, COPD, atherosclerosis, and CHF (13). MMPs degrade the basement membrane and allow tumor cells to invade the stroma, therefore contributing to local and distant tumor invasion. In bone, MMPs have been shown to play an important role in bone matrix turnover in metastatic prostate cancer (15). Research by Nelson et al suggests that MMPs are not only linked to tumor invasion and metastasis, but they function in a manner that creates and maintains a pro-tumor milieu in the microenvironment of the growing tumor. Further, Nelson et al suggest that a positive correlation exists between tumor aggressiveness and the level of MMPs in melanoma, colon adenocarcniomas and squamous cell carcinomas (16).

The MMPs are categorized as collagenases (MMP-1, -8, $-13,-18)$ which degrade interstitial collagens, and gelatinases (MMP-2, -9) which degrade type IV basement collagen and contribute to angiogenesis. In addition, there are stromelysins (MMP-3, -10, -11) and membrane-type MMPs (MMP-14-17) which degrade other components of the ECM or activate some MMPs (17-20). Furthermore, the regulation of MMPs is controlled in part by both inhibitors and inducers called tissue-specific inhibitors of matrix metalloproteinases (TIMPs) and extracellular matrix metalloprotinease inducer (EMMPRIN).

The purpose of this study was to explore a sample of high grade soft tissue sarcomas to determine the presence and amount of MMP-1, -2, -8, -9, -13; TIMP-1, -2; and EMMPRIN. We then correlated that information with clinical outcome to determine if a relationship exists between the expression of these enzymes and long-term survival in persons with HGSTS. At present, the literature lacks a quantitative description of MMPs, TIMPs and EMMPRIN present in the most common HGSTS. Some studies have examined MMP protein expression using immunohistological approaches which are semiquantitative (17). Our study uses real-time PCR to analyze MMP, TIMP and EMMPRIN gene expression. Real-time PCR is absolutely quantitative, and by comparing the expression of our genes of interest to the $18 \mathrm{~S}$ ribosomal RNA index gene in the same tumor tissue, we are able to normalize all tumor samples against each other. This approach provides a more consistent and precise quantitation of MMP, TIMP or EMMPRIN expression between all experimental samples.

\section{Materials and methods}

Case identification. Review of the tumor database of the senior author (RPW) at the University of Texas Health Science Center in San Antonio identified 140 patients with high grade soft tissue sarcomas diagnosed between 1995 and 2003. Inclusion in this study was based upon availability of adequate paraffin-embedded tissue samples and pathology slides in patients diagnosed with HGSTS at University Hospital from 1995 to 2003. Additional criteria include: availability of clinical data, age $>18$ years, and tumors not previously treated with chemotherapy or radiation. The study was then performed on 41 specimens divided into 29 malignant fibrous histiocytomas, 3 liposarcomas and 11 synovial sarcomas. Ten paraffinembedded skin tissue samples from autopsy specimens obtained during the same time period as the tumor specimens were identified, and once confirmed to have no cancer diagnosis were used as controls.

Viable tumor identification. A musculoskeletal tumor pathologist reviewed the complete set of available slides for each case and classified tumor type by using World Health Organization definitions. A few cases of high grade myxofibrosarcoma and two cases of a high grade fibrosarcoma were included in the MFH category. A representative H\&E slide with well preserved, viable appearing tumor histology was selected and the surface area of tissue suitable for RNA extraction was marked on the slide.

RNA extraction. RNA was extracted from the selected region of the paraffin-embedded tissue samples, as first described by Godfrey et al (18). The region of interest on the paraffin block was identified by comparing it to the region marked by the pathologist on the histologic slide. The marked area was carefully cut out of the paraffin block and the small amount of tissue obtained was diced into very small flakes which 
Table I. MMP data for all tumors.

\begin{tabular}{|c|c|c|c|c|c|}
\hline & MFH & Liposarcoma & Synovial sarcoma & All & $\mathrm{P}$-value $\mathrm{a}^{\mathrm{a}}$ \\
\hline MMP 1 (n) & 27 & 11 & 3 & 41 & 0.60 \\
\hline Mean (SD) & $25.5(13)$ & $21.6 \quad(7.1)$ & $30.8(23.9)$ & $24.8(12.5)$ & \\
\hline Median & 22.8 & 22.2 & 42 & 22.8 & \\
\hline MMP 2 (n) & 26 & 11 & 3 & 40 & 0.07 \\
\hline Mean (SD) & $28.6(11.9)$ & $18.8(11.3)$ & $29.1(19)$ & $25.9(12.7)$ & \\
\hline Median & 29.3 & 18.6 & 39.8 & 27.9 & \\
\hline MMP 8 (n) & 27 & 11 & 3 & 41 & 0.73 \\
\hline Mean (SD) & $33.1(26.7)$ & $25.1(13.1)$ & $25.2(21)$ & $30.3(23.3)$ & \\
\hline Median & 29.9 & 23.8 & 30 & 29.9 & \\
\hline MMP 9 (n) & 26 & 11 & 3 & 40 & 0.57 \\
\hline Mean (SD) & $18.8(12.7)$ & $15.5(10.2)$ & $21.7 \quad(7.8)$ & $18.1(11.7)$ & \\
\hline Median & 15.6 & 11.4 & 20.6 & 14.8 & \\
\hline MMP 13 (n) & 26 & 11 & 3 & 40 & 0.20 \\
\hline Mean (SD) & $29.9(10.2)$ & $23.9(12.7)$ & $19.5(11.8)$ & $27.5(11.3)$ & \\
\hline Median & 30.4 & 23.6 & 15.5 & 27.8 & \\
\hline TIMP 1 (n) & 24 & 9 & 3 & 36 & 0.33 \\
\hline Mean (SD) & $22.4(12.2)$ & $17.9(20)$ & $25.3(32.3)$ & $21.5(15.9)$ & \\
\hline Median & 20.7 & 8 & 7.2 & 17.5 & \\
\hline TIMP 2 (n) & 27 & 11 & 3 & 41 & 0.97 \\
\hline Mean (SD) & $32.5(12.7)$ & $35.2(19.4)$ & $32(5.2)$ & $33.2(14.2)$ & \\
\hline Median & 29 & 36.2 & 29.1 & 29.5 & \\
\hline EMMPRIN (n) & 26 & 11 & 3 & 40 & 0.08 \\
\hline Mean (SD) & $25.4(15.1)$ & $18.5(11.6)$ & $9.1 \quad(9.4)$ & $22.3(14.5)$ & \\
\hline Median & 24.7 & 17.2 & 6.7 & 21.5 & \\
\hline
\end{tabular}

${ }^{a}$ Kruskal-Wallis test with 2 degrees of freedom to test for differences between the three types of sarcomas.

were placed into a 5-ml xylene resistant tube. The tissue was then deparaffinized by incubation in xylene at $37^{\circ} \mathrm{C}$ for $20 \mathrm{~min}$, centrifuged, incubated a second time with xylene for $20 \mathrm{~min}$ and then washed in ethanol two times. The ethanol was washed with a digestion buffer consisting of $1 \mathrm{~mol} / \mathrm{l}$ of guanidinium thiocynate, $25 \mathrm{mmol} / \mathrm{l}$ of 2-mercaptoethanol, $0.5 \%$ sarcosyl and $20 \mathrm{mmol} / \mathrm{l}$ of Tris- $\mathrm{HCl}(\mathrm{pH} 7.5)$. The deparaffinized tissue was then vortex mixed with a digestion solution consisting of $80 \mu \mathrm{l}$ of $60 \mathrm{mg} / \mathrm{ml}(20 \mathrm{U} / \mathrm{mg})$ proteinase $\mathrm{K}$ and $720 \mu \mathrm{l}$ of the digestion buffer. This mixture/suspension was incubated overnight at $55^{\circ} \mathrm{C}$. An $80-\mu 1$ aliquot of Proteinase $\mathrm{K}$ was then added and incubated overnight at $55^{\circ} \mathrm{C}$ for each of the next two days. RNA was extracted with an equal volume of $70 \%$ phenol ( $\mathrm{pH} \mathrm{4.3)/30 \%} \mathrm{chloroform} \mathrm{and} \mathrm{this} \mathrm{centrifuged} \mathrm{at}$
$14000 \mathrm{rpm}$ for $5 \mathrm{~min}$. The aqueous phase was placed into a new tube and RNA was precipitated with the addition of an equal volume of isopropanol containing $2 \mu \mathrm{g}$ of glycogen, at $-20^{\circ} \mathrm{C}$ for $30 \mathrm{~min}$. The samples were then centrifuged at $14000 \mathrm{rpm}$ for $10 \mathrm{~min}$, washed with $70 \%$ ethanol and allowed to air dry. The extraction/purification was completed by diluting in DEPC water and TRIzol extraction according to the manufacturer's instructions (Invitrogen Corp., Carlsbad, CA).

RT-PCR technique. The relative expression of collagenases (MMP-1, -8, -13), gelatinases (MMP2, -9), TIMP-1 and TIMP-2, and EMMPRIN was determined using real-time PCR with the Applied Biosystems PRISM 7000 Sequence 
Detection system. The manufacturer protocol was followed. 20 ng RNA samples were pipetted into 96-well plates in triplicate. Into each well, $0.625 \mu 1$ of Multi-Scribe reverse transcriptase, $12.5 \mu 1$ of Master Mix containing AmpliTaq Gold DNA polymerase, and $1.25 \mu 1$ of the specific primerprobe Assay-on-Demand ${ }^{\mathrm{TM}}$ mixture for each gene tested (Applied Biosystems, Foster City, CA). The catalog numbers for the human EMMPRIN, MMP-1, MMP-2, MMP-8, MMP-9, MMP-13, TIMP-1, TIMP-2 and 18S rRNA are respectively, Hs00174305_ml, Hs00233958_ml, Hs00234422_ml, Hs00233972_ml, Hs00234579_ml, Hs00233992_ml, Hs00234278_ml, 4319413E. DEPC-treated water was added to each well bringing the total volume to $25 \mu \mathrm{l}$ and the plate lightly vortexed for $3 \mathrm{~min}$. The plate was centrifuged to force the liquid to the bottom of the plate and the plate was then placed into the PRISM 7000. PCR conditions included: reverse transcription at $48^{\circ} \mathrm{C} \times 30 \mathrm{~min}$, denaturation at $95 \mathrm{C} \mathrm{x}$ $10 \mathrm{~min}$, amplification for 40 cycles of denaturation at $95^{\circ} \mathrm{C} \mathrm{x}$ $15 \mathrm{sec}$ and annealing/extension at $60^{\circ} \mathrm{C}$ for $60 \mathrm{sec}$. Standard curves for each gene tested were constructed using known quantities of RNA and all genes compared to 18S rRNA housekeeping gene as a normalizer. Data analysis of real-time PCR results was conducted using the standard curve method described in the Applied Biosystems PRISM 7000 sequence detection system user manual and additionally validated following the mathematical model of Pfaffl (19). RT-PCR analysis was run in triplicate. Protease gene expression was expressed as relative to the $18 \mathrm{~S}$ rRNA housekeeping gene.

\section{Results}

The analysis of data to determine the presence and amount of the various MMPs studied was conducted primarily through tables of summary statistics. Table I describes the MMP values obtained for all the high grade soft tissue sarcomas studied, divided into groups by tumor type: MFH, liposarcoma and synovial sarcoma. Each row provides the number of observations in that category (n), the mean and standard deviation (SD) for each category and the median for each of MMP-1, MMP-2, MMP-8, MMP-9, MMP-13, TIMP-1, TIMP-2, and EMMPRIN. Additionally, KruskalWallis non-parametric tests with 3 and 2 degrees of freedom were used to test for differences in the MMPs among the different sarcoma types. No statistically significant differences among the HGSTS were observed in regards to amount of MMP expressed.

Table II describes the mean and median as well as standard deviation of the MMP values obtained for all tumors when compared to controls. MMP-8 and MMP-13 showed statistically significant differences between HGSTS samples and controls. MMP-8 had a higher expression in tumor samples than in controls, while MMP-13 had significantly lower expression in tumor samples than in the control samples. The clinical significance of these differences is unknown.

In order to determine if a relationship exists between quantity of markers studied and disease-free survival, statistical methods from survival analysis were used. Two different outcomes were examined: death and the first event of recurrence or metastasis. For each of these outcomes, KaplanMeier survival estimate plots (Figs. 1 and 2) were constructed
Table II. MMP data tumors vs controls.

\begin{tabular}{|c|c|c|c|}
\hline & All tumors & Controls & P-value \\
\hline MMP 1 n & 41 & 9 & 0.62 \\
\hline Mean (SD) & $24.8(12.5)$ & $21.8(5.6)$ & \\
\hline Median & 22.8 & 21 & \\
\hline MMP 2 n & 40 & 9 & 0.19 \\
\hline Mean (SD) & $25.9(12.7)$ & $20.8(8.6)$ & \\
\hline Median & 27.9 & 23.6 & \\
\hline MMP 8 n & 41 & 9 & 0.03 \\
\hline Mean (SD) & $30.3(23.3)$ & $18.5(8.8)$ & \\
\hline Median & 29.9 & 23.6 & \\
\hline MMP 9 n & 40 & 9 & 0.41 \\
\hline Mean (SD) & $18.1(11.7)$ & $13.6(8.8)$ & \\
\hline Median & 14.8 & 15.2 & \\
\hline MMP 13 n & 40 & 9 & 0.04 \\
\hline Mean (SD) & $27.5(11.3)$ & $42.5(22.4)$ & \\
\hline Median & 27.8 & 38.6 & \\
\hline TIMP $1 \mathrm{n}$ & 36 & 8 & 0.48 \\
\hline Mean (SD) & $21.5(15.9)$ & $15.4(10.8)$ & \\
\hline Median & 17.5 & 14.4 & \\
\hline TIMP 2 n & 41 & 9 & 0.71 \\
\hline Mean (SD) & $33.2(14.2)$ & $33.4(18.6)$ & \\
\hline Median & 29.5 & 33.4 & \\
\hline EMMPRIN n & 40 & 9 & 0.73 \\
\hline Mean (SD) & $22.3(14.5)$ & $23.4(14)$ & \\
\hline Median & 21.5 & 29.4 & \\
\hline
\end{tabular}

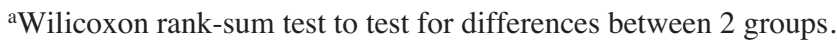

to present the general trend of events. The figures also provide summary information such as the median survival time and its corresponding 95\% confidence interval (if these values could be estimated from the data) and the percentages of patients known to experience the event of interest versus the percentage of patients that were censored (lost to followup before the event occurred or never experienced the event).

The observations were also broken up into four roughly equal groups based on quartiles of a particular MMP. A separate group division was constructed based on each MMP. Kaplan-Meier survival estimate plots were produced with a line representing each of the four quartiles drawn onto the same plot. This type of plot was constructed for each MMP for each of the event categories, producing a total of 16 figures. Figs. 3 and 4, showing the survival estimate plots for MMP-8 are included for review. At the bottom of these graphs, the p-value for the log-rank test is displayed. The 


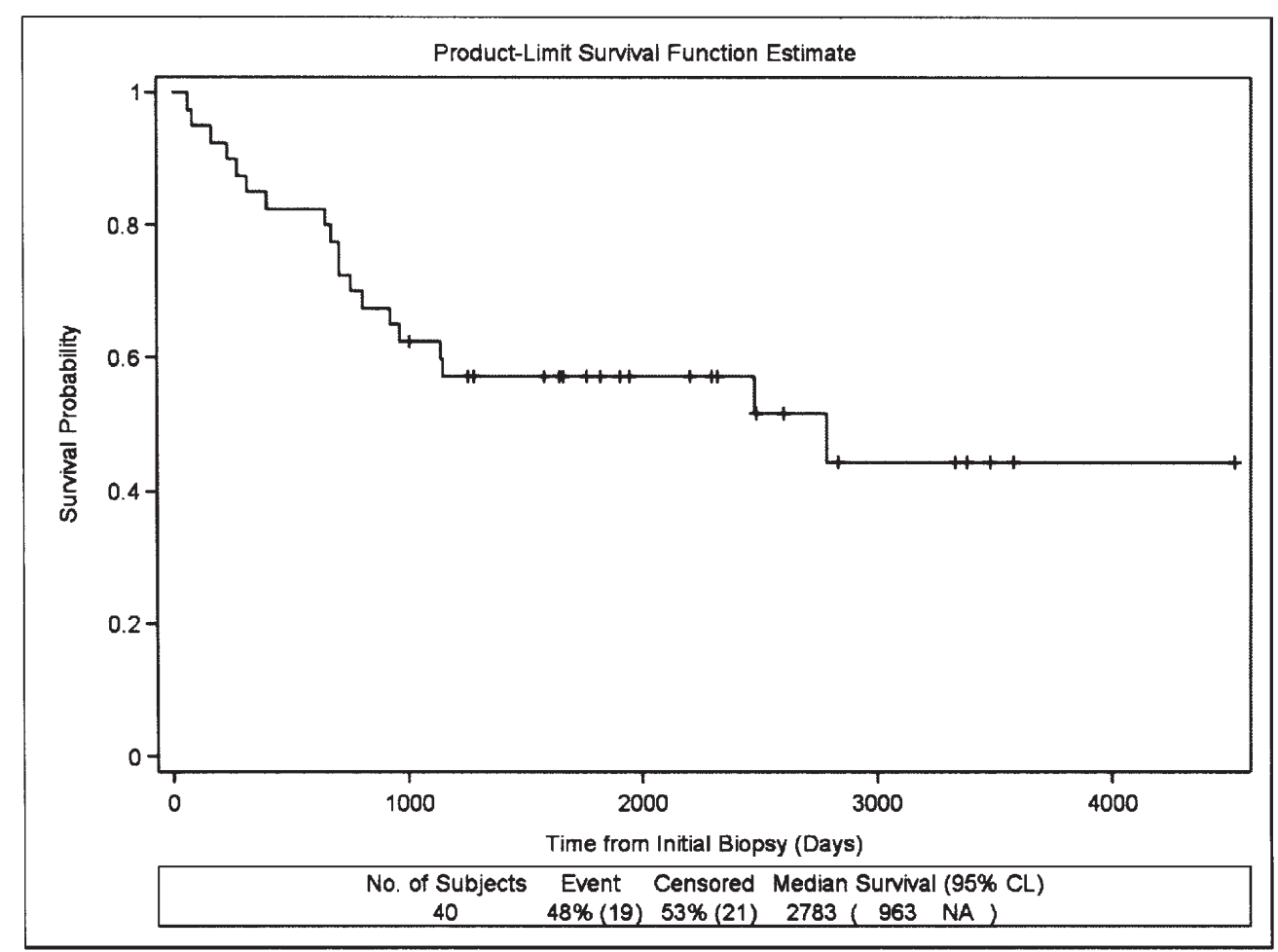

Figure 1. Time to death over all subjects. Survival time from initial biopsy was measured for all patients. The Kaplan-Meier method to estimate a trend of overall survival for the study cohort was used. Tick marks represent loss to follow-up (censored observations).

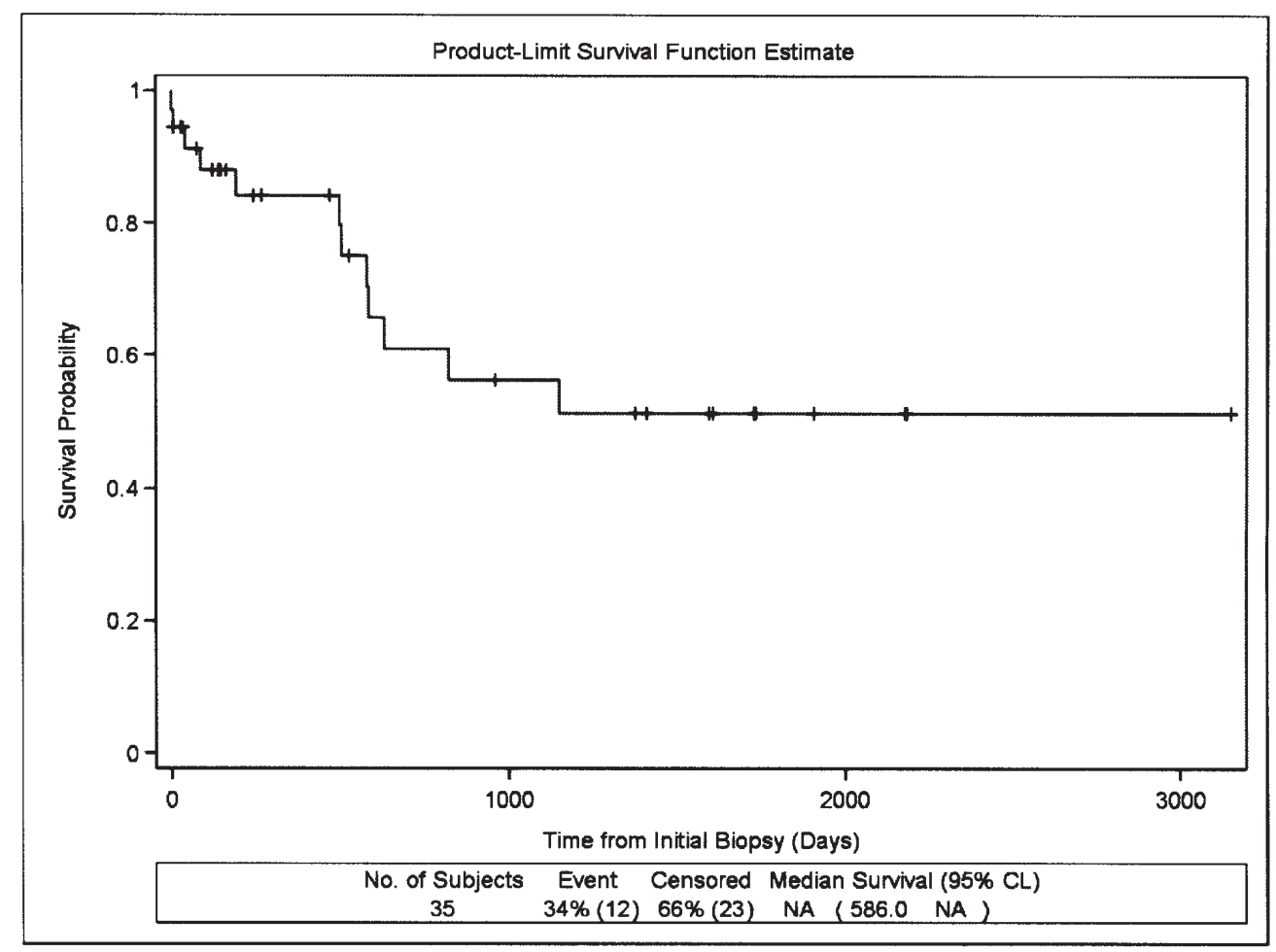

Figure 2. Time to first event of recurrence or metastasis in all subjects. Time to recurrence or metastasis was measured in days for all patients. The time to the first occurrence of metastasis or recurrence is summarized for all patients using the Kaplan-Meier survival estimate. Tick marks represent loss to follow-up (censored observations).

log-rank test assesses differences in survival distributions between the four quartiles of the respective MMP. The p-values from the log-rank test as well as observations from the graph indicate that from this data set there are few detectable differences in either of the survival outcomes among individuals with differing levels of MMPs. 


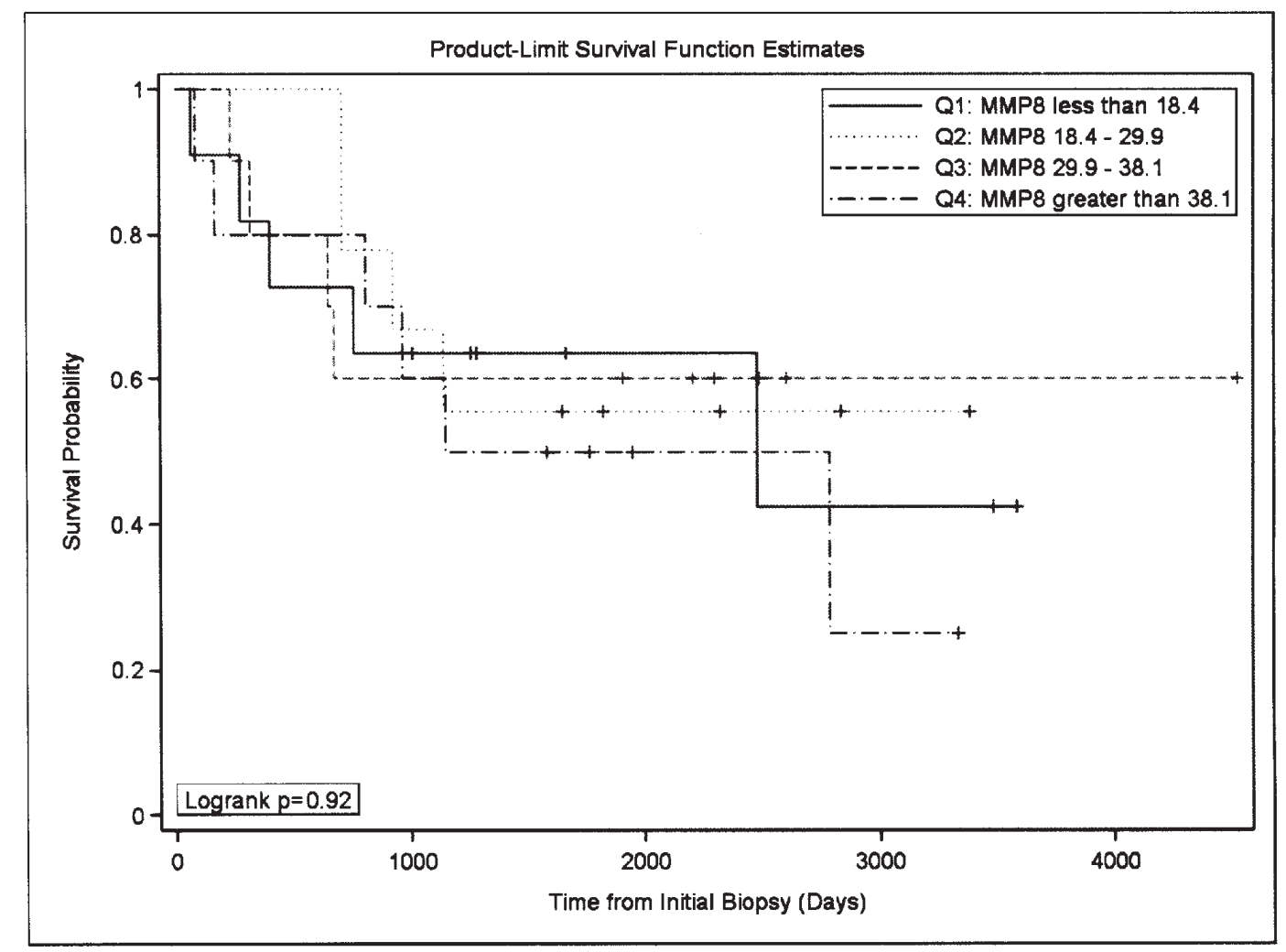

Figure 3. Time to death by quartile of MMP-8. Patients were divided into four roughly equal groups based on quartiles of MMP8 measurements. The survival trends were similar between groups with varying levels of MMP-8. Tick marks represent loss to follow-up (censored observations).

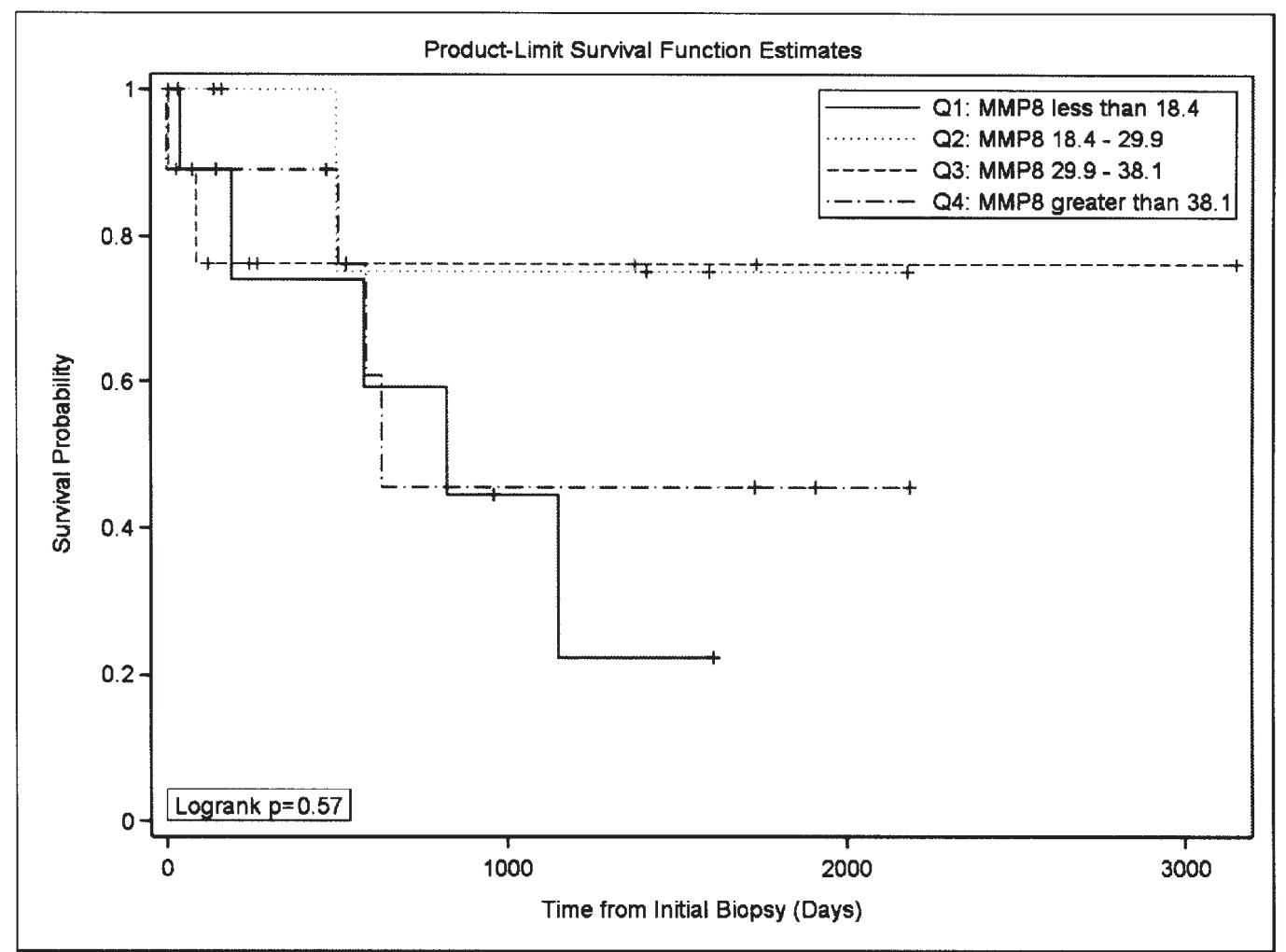

Figure 4. Time to first event of recurrence or metastasis by quartile of MMP-8. Patients were divided into four roughly equal groups based on quartiles of MMP-8 measurements. The times to the first occurrence of metastasis or recurrence by level of MMP- 8 are shown. There are no significant differences between the groups based on the log-rank test. Tick marks represent loss to follow-up (censored observations). 


\section{Discussion}

The expression of the matrix metalloproteinases was evaluated in each tumor relative to the other tumor types to determine if a unique pattern of expression exists that correlates with disease-free survival. The data were also compared to skin sample controls taken from autopsy specimens with no documented malignancy. Limitations of this study include limited sample size and incomplete follow-up information.

The expression of MMPs and TIMP has been reported mainly in commonly occurring carcinomas including, breast, prostate, lung and colorectal cancers. Increased levels of MMP-2 have been linked to capsular effraction and stage in prostate cancer (21). Increased MMP-2, -9, -13 and decreased TIMP-1 was found to be significantly different between the patients with and without metastasis in prostate cancer (22). MMP-1, -2, -3, -7, -9 were elevated in colorectal cancers $(23,24)$. Furthermore, Moran et al showed that a decrease in the MMP inhibitor TIMP-1 correlated with a poor outcome in colorectal cancer patients (24). EMMPRIN (the extracellular inducer of MMPs) has been shown to induce MMP-1, -2, -3. Caudroy et al showed in vitro that EMMPRIN producing tumors can stimulate MMPs both in the stroma and in the tumor cells, thus promoting tumorigenesis and metastasis (26). Another study in ovarian carcinoma showed coexpression of an EMMPRIN and MMP-1, -9 and correlated this with poor survival (27).

Some research has been done on the expression of MMPs and TIMPs in soft tissue sarcomas. Benassi et al studied MMP-2, -9 and TIMP-2 expression as a prognostic indicator in STS using the non-quantitative methods of immunohistochemistry and immunoblotting (27). Their study used frozen and paraffin-embedded tumor samples from 29 liposarcomas, 29 synovial sarcoma cases and 15 malignant peripheral nerve sheath tumors and found a correlation between elevated MMP-2 activity and increased disease-free survival $(\mathrm{p}=0.0005)$. These results must be interpreted cautiously as immunohistochemistry is nonquantitative and subjective. The cut-off for determining increased expression of MMP-2 and -9 was that $25 \%$ of the cells appeared positive. The fact that these markers were present in $25 \%$ of the cells does not mean that their activity is increasing the metastatic potential of the tumor. These authors reported that size and grade were also related to prognosis (well known components of a grading system from STS) while sex, age, and treatment were not related to disease-free survival (27). Roebuck et al studied MMP-1, -3, $-8,-10,-11,-13,-14$ and TIMP-2 expression in benign soft tissue neoplasms, fibromatosis and sarcomas using immunocytochemical analysis and zymography (17). Their findings suggest that expression of TIMP-2 could be important in soft tissue sarcomas, but otherwise their data did not support the hypothesis that the invasive nature of sarcomas is due to elevation of individual MMPs. Rather, their conclusion was that there is much variability in the expression of MMPs in different tumor types.

Our data confirm the conclusion of Roebuck et al that there is significant variability in the expression of MMPs within a specific histologic type of HGSTS as well as among different tumor types tested in this study. Our data also confirm the work of Maguire et al who report their study using PCR to evaluate expression of MMP-2, -9 and TIMP -1, -2 in 12 fresh-frozen surgical soft tissue sarcoma specimens (histologic variety not disclosed). They concluded that while expression of MMP-2 and -9 and TIMP- 1 and -2 were detected in the tumor specimens, the levels did not correlate with disease-free survival (28).

The lack of association between MMPs and disease-free survival in soft tissue sarcomas in contrast to the observed relationship in carcinomas may be related to fundamental differences between sarcomas and carcinomas. Carcinomas are tumors which arise from tissues derived from the embryonic endoderm. During embryonic development, endodermal tissues differentiate into the respiratory and gastrointestinal systems as well as many glandular structures. Sarcomas are tumors which arise from the embryonic mesoderm and differentiate to form bones, connective and vascular tissues. These two very different primitive tissues have phenotypic and genotypic differences which likely lead to different behavior. Thus, MMPs may play a significant role in the regulation of carcinomas without having any effect on sarcoma cells. MMPs, with their inducers and inhibitors, exist in a balance in normal human tissues. More research is necessary to fully explore the interactions and behavior of these potent enzymes and other differences in behavior between carcinomas and sarcomas.

\section{Acknowledgements}

The authors would like to thank Dr David Dean for assistance with experimental design, and Dan Chan, Elizabeth Sweeney and Brian Weatherford for technical assistance.

\section{References}

1. Pollock R: Soft tissue sarcomas. American Cancer Society Atlas of Clinical Oncology. BC Decker, London, 2002.

2. Gustafson P: Soft tissue sarcoma: epidemiology and prognosis in 508 patients. Acta Orthop Scand Suppl 259: 1-31, 1994

3. Campanacci M: Bone and Soft Tissue Tumors. 2nd edition. Piccin Nuova Libraria, Padova, 1999.

4. American Cancer Society: Cancer Statistics 2006. http://www. cancer.org/

5. Fletcher C, Unni K and Mertens F (eds): World Health Organization Classification of Tumours. Pathology and Genetics of Tumours of Soft Tissue and Bone. IARC Press, Lyon, 2002.

6. Cormier J: Soft tissue sarcomas. CA Cancer J Clin 54: 94-109, 2004.

7. Ham S, van der Graaf W, Pras E., Molenaar W, van den Berg E and Hoekstra H: Soft tissue sarcoma of the extremities. A multimodality diagnostic and therapeutic approach. Cancer Treat Rev 24: 373-391, 1998.

8. Takey M, Yoshimura T, Leonard E, Kato T, Okabe H and Takahashi K: Production of monocyte chomattractacnt protein-1 by malignant fibrous histiocytoma: relation to the origin of histiocyte-like cells. Exp Mol Pathol 54: 61-71, 1991

9. Kartha S and Bumpous J: Synovial cell sarcoma: diagnosis, treatment, and outcomes. Laryngoscope 112: 1979-1982, 2002.

10. Pisters P: Staging and prognosis. In: American Cancer Society Atlas if Clinical Oncology: Soft Tissue Sarcomas. Pollock RE (ed). BC Decker, Inc., Hamilton, Ontario, pp80-88, 2002.

11. Cawley LJ and Matrisian LM: Matrix metalloproteinases: they're not just for matrix anymore! Curr Opin Cell Biol 13: 534-540, 2001.

12. Delaisse J, Engsig M, Everts V, Overejo M, Ferreras M, Lund L, Vu T, Werb Z, Winding B, Lochter A, Kardsal M, Troen T, Kirkegaard T, Lenhard T, Heegaard N, Neff L, Baron R and Foged N: Proteinases in bone resorption: obviousand less obvious roles. Clin Chim Acta 291: 223-234, 2000.

13. Mandal M, Mandal A, Das S, Chakraborti T and Chakraborti S: Clinical implications of matrix metalloproteinases. Mol Cell Biochem 252: 305-329, 2003. 
14. Papathoma A, Zoumpourlis V, Balmain A and Pintzas A: Role of matrix metalloproteinase- 9 in progression of mouse skin carcinogenesis. Mol Carcinog 31: 74-82, 2001.

15. Nemeth J, Yousif R, Herzog M, Che M, Upadhyay J, Shekarriz B, Bhagat S, Mullins C, Fridman R and Cher M: Matrix metalloproteinase activity, bone matrix turnover, and tumor cell proliferation in prostate cancer bone metastasis. J Natl Cancer Inst 94: 17-25, 2002.

16. Nelson A, Fingelton B, Rothenberg M and Matrisian L: Matrix metalloproteinases: biologic activity and clinical implications. J Clin Oncol 18: 1135-1149, 2000.

17. Roebuck MM, Helliwell TR, Chaudhry IH, Kalogrianitis S, Carter S, Kemp GJ, Ritchie DA, Jane MJ and Frostick SP: Matrix metalloproteinase expression is related to angiogenesis and histologic grade in spindle cell soft tissue neoplasms of the extremities. Am J Clin Pathol 123: 405-414, 2005.

18. Godfrey T, Kim S, Chavira M, Ruff D, Warren R, Gray J and Jensen R: Quantitative mRNA expression analysis from formalinfixed, paraffin-embedded tissues using 5 ' nuclease quantitative transcription polymerase chain reaction. J Mol Diagn 2: 84-91, 2000.

19. Pfaffl MW: A new mathematical model for relative quantification in real-time RT-PCR. Nucleic Acids Res 29: e45, 2001.

20. Semaan M, Jovenin N, Birembaut P, Menard J and Staerman F: Prognostic value of stromal immunolabelling by MMP-2, MT1-MMP and TIMP-2 in clinically localized prostate cancer. Prog Urol 15: 250-254, 2005.

21. Morgia G, Falsaperla M, Malaponte G, Madonia M, Indelicato M, Travali S and Mazzarino MC: Matrix metalloproteinases as diagnostic (MMP-13) and prognostic (MMP-2, MMP-9) markers of prostate cancer. Urol Res 33: 44-50, 2005.
22. Pesta M, Holubec L Jr, Topolcan O, Cerna M, Rupert K, Holubec LS, Treska V, Kormunda S, Elgrova L, Finek J and Cerny R: Quantitative estimation of matrix metalloproteinases 2 and 7 (MMP-2, MMP-7) and tissue inhibitors of matrix metalloproteinases 1 and 2 (TIMP-1, TIMP-2) in colorectal carcinoma tissue samples. Anticancer Res 25: 3387-3391, 2005.

23. Langenskiold M, Holmdahl L, Falk P and Ivarsson ML: Increased plasma MMP-2 protein expression in lymph nodepositive patients with colorectal cancer. Int J Colorectal Dis 20: 245-252, 2005.

24. Moran A, Iniesta P, Garcia-Aranda C, De Juan C, Diaz-Lopez A, Sanchez-Pernaute A, Torres AJ, Diaz-Rubio E, Balibrea JL and Benito M: Clinical relevance of MMP-9, MMP-2, TIMP-1 and TIMP-2 in colorectal cancer. Oncol Rep 13: 115-120, 2005.

25. Caudroy S, Polette M, Nawrocki-Raby B, Cao J, Toole B, Zucker $S$ and Birembaut P: EMMPRIN-mediated MMP regulation in tumor and endothelial cells. Clin Exp Metastasis 19: 697-702, 2002.

26. Davidson B, Goldberg I, Berner A, Kristensen G and Reich R: EMMPRIN (extracellular matrix metalloproteinase inducer) is a novel marker of poor outcome in serous ovarian carcinoma. Clin Exp Metastasis 20: 161-169, 2003.

27. Benassi MS, Gamberi G, Magagnoli G, Molendini L, Ragazzini P, Merli M, Chiesa F, Balladelli A, Manfrini M, Bertoni F, Mercuri M and Picci P: Metalloproteinase expression and prognosis in soft tissue sarcomas. Ann Oncol 12: 75-80, 2001.

28. Maguire PD, Qi WN, Lallemand R and Scully S: Gelatinase and inhibitor expression in soft tissue sarcomas:lack of correlation with distant metastasis. Oncology 59: 139-144, 2000. 